\title{
A modified faecal harness for grazing goats on mediter- ranean shrublands
}

\author{
M.D. YIAKOULAKI AND A.S. NASTIS
}

Authors are research scientist and professor, Department of Range Science (236), Aristotle University, 54006 Thessaloniki, Greece.

\begin{abstract}
A modified faecal harness for goats was specially designed for grazing conditions in dense mediterranean shrublands and subsequently tested successfully for total faecal collection. The details of design and collection are presented.
\end{abstract}

Key Words: faecal harness, goat, shrublands

During the last few years considerable research has been carried out with grazing goats on mediterranean shrublands in Greece (Nastis 1982, Papachristou 1990, Yiakoulaki 1992, Yiakoulaki and Nastis 1995, Yiakoulaki and Nastis 1996, Yiakoulaki et al. 1997) specially related to stocking rate, diet selection, nutritive value, and intake. Most shrublands in the mediterranean zone are dominated by kermes oak $(Q$. coccifera L.) very often dense to be penetrated or reached by goats. Previous faecal harnesses designed for goats and deer (McCammon-Feldman 1980, Malechek et al., 1980, Pfister 1985) have been relatively heavy structures using too much canvas. A different style and different materials are needed for a durable harness for goats on nutrition studies on mediterranean shrublands. Yiakoulaki (1992) modified the harness of Pfister (1985) to suit the local conditions of the research area by eliminating canvas completely to enable the animals to move around more freely in the dense shrublands. The faecal harness was designed to fit well on goats without disturbing their mobility, bipedal stance, and consequently their grazing behavior. A satisfactory faecal harness must allow for only minimal faecal losses.

\section{Design}

The faecal harness (Fig. 1) is comprised of 2 parts: A and B. Part A (Fig. 1a) consists of 3 main bands namely neck, breast, and lower abdomen band. On these 3 bands have been attached 19 leather straps with buckles. Their dimensions and design is such that they could be buckled together around the goats' body. The part B of the faecal harness includes a rump band and the faecal bag. The rump band with its 4 straps (Fig. 1b) can be buckled with the straps of the lower abdomen band. The faecal bag is

Manuscript accepted 20 Jan. 1998.

\section{Resumen}

Se diseñó una bolsa adaptada para recoger la materia fecal de las cabras especialmente bajo condiciones de pastoreo entre los densos arbustos mediterráneos y a continuación se probó con éxito. Se presentan los detalles del diseñó y de le recolección.

made from tough, durable plastic and attaches to the rump band. When tied around the goat, it covers the anal opening and the tail. In order to keep the faecal bag clean, a lining bag is inserted and secured with buttons (Fig.1c). The faecal and the interior lining

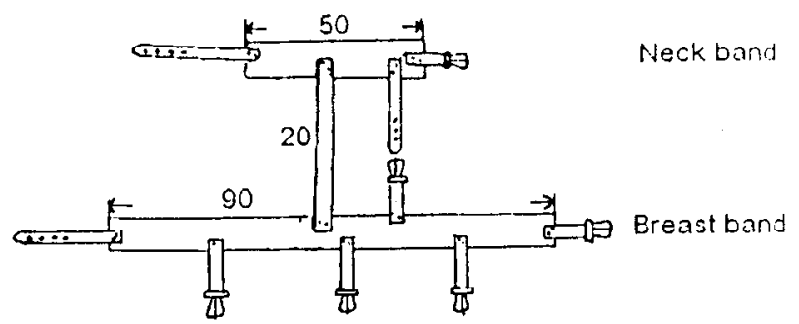

(a)

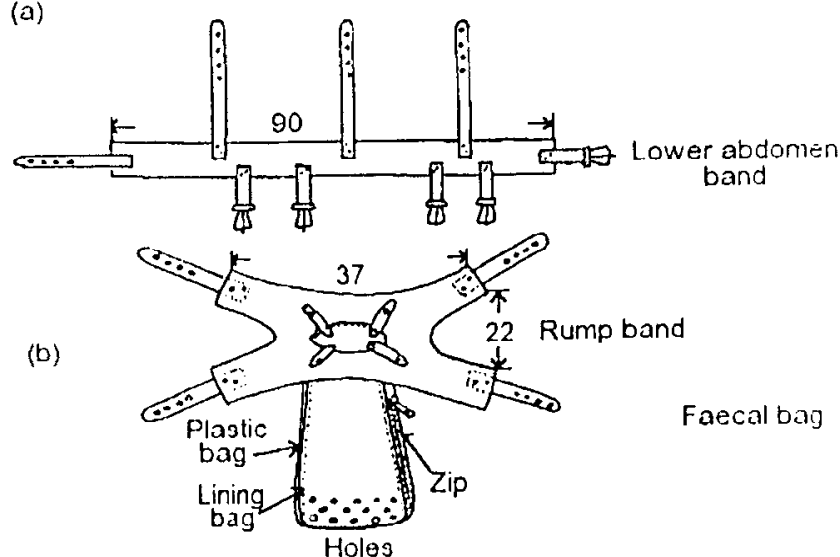

(c)

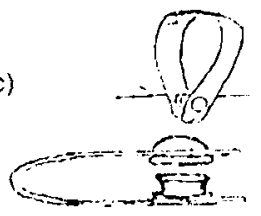

Fig. 1. Pattern and dimensions (in $\mathrm{cm}$ ) for a faecal harness fitted for a $40 \pm 5$ kg goat. 


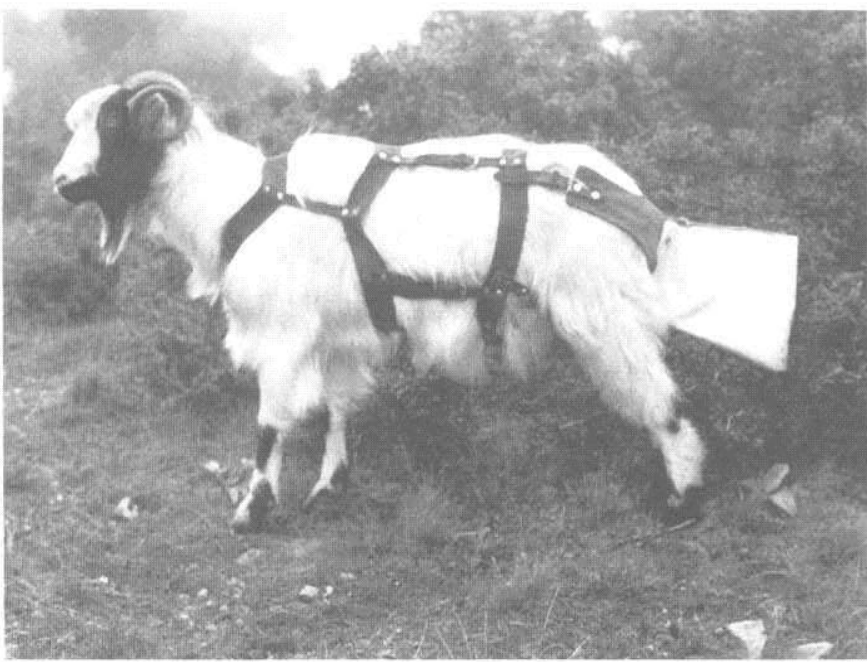

Fig. 2. View of faecal harness fitted on goat grazing on a mediterranean shrubland.

bag have holes in the bottom, to let the urine flow out. With this design the lining and consequently the plastic bags retain only faecal material. The lining bag can be removed from the zip provided on the side of plastic bag (Fig. 1b) twice a day. The entire harness and faecal bag weighs $730 \mathrm{~g}$.

\section{Application and Evaluation}

This equipment was tested in several experiments (Yiakoulaki 1992, Yiakoulaki and Nastis 1996, Yiakoulaki et al. 1997) in Chrysopigi Forest Research Experimental Station in Northern Greece. Shrublands were generally dence with a canopy cover ranging from 53 to $66 \%$.

The faecal harness (Fig. 2) was fitted on twelve 2 year old, meat type, female, local goats weighing $40 \pm 5 \mathrm{~kg}$. Goats were fitted with faecal harnesses for a 3-day adaptation period followed by a 6-day faecal collection period. In total approximately 580 animal-days estimates of faecal production were obtained under range conditions in different seasons from 1989-1994. Faeces were collected every 12 hours, and all attempts were successful, resulting in less than $6 \%$ wastage across trials.

In order to test if faeces were being lost from the faecal harness, four goats were placed over night in a stable free of faecal materials. It was observed on the next day that no faeces were lost. This experiment was repeated for 3 consecutive nights. Observations of free-grazing goats on dense shrublands indicated that faeces were lost only if bags were not properly adjusted. Rarely have faecal material been lost in practice and only when harnesses were lost. During periods of high diet quality when faecal pellets were soft, some faecal losses with urine washes were observed. These samples were discarded very rarely aberrant animals which produced soft faeces replaced. It was also observed that by using the present faecal harness on grazing goats, their mobility and bipedal browsing stance was not impaired. Occasionally, in the beginning of the experiments the non-harnessed goats chewed the straps of the harnessed goats and pulled them off. During the 9-days duration of the experiment most of the harnessed goats did not display signs of stress or discomfort. Therefore, the harnesses did not modify the grazing behavior of goats.

\section{Literature Cited}

Malechek, J.C., K.O. Fulgham, and M.A. Smith. 1980. A faecal collection apparatus for deer nutrition studies. J. Range Manage. 33:398-399.

McCammon-Feldman, B. 1980. A critical analysis of tropical savanna forage consumption and utilisation by goats. Ph.D. Dissertation, Univ. Illinois, Urbana, Ill.

Nastis, A.S. 1982. Nutritive value of oak browse $(Q$. coccifera) foliage for goats at various phenological stages. Professorship Dissertation (in Greek with English abstract). Aristotle University. Thessaloniki, Greece.

Papachristou, T.G., 1990. Botanical composition and nutritive value of goat diets on shrublands with different proportions of shrubby and herbaceous species. Ph.D. Diss. (in Greek with English abstract). Aristotle University. Thessaloniki, Greece.

Pfister, J.A. 1985. An effective faecal harness for free-grazing goats. J. Range Manage. 38:184-185.

Yiakoulaki, M.D. 1992. Effect of different proportions of shrubby and herbaceous vegetation on intake of goats. Ph.D. Dissertation (in Greek with English abstract). Aristotle University. Thessaloniki, Greece.

Yiakoulaki, M. D. and A.S. Nastis. 1995. Intake by goats grazing kermes oak shrublands with varying cover in Northern Greece. Small Ruminant Res. 17:223-228.

Yiakoulaki, M. D. and A.S. Nastis. 1996. Effect of stocking rate on intake and gain of goats grazing in kermes oak shrubland, p. 243-247. In: N.P. Zervas and J. Hatziminaoglou (eds), Proceedings of the International Symposium on the optimal exploitation of marginal Mediterranean areas by extensive ruminant production systems. Thessaloniki. Greece.

Yiakoulaki, M.D., Papadoyannis, I.N. and A.S. Nastis. 1997. Determination of marker chromic oxide in faeces of grazing goats on mediterranean shrublands by aas. Anim. Feed Sci. and Tech. 67:163168. 